\title{
The Hamburg Online Math Test MINTFIT for Prospective Students of STEM Degree Programmes
}

\author{
Helena Barbas, Institute of Mathematics, Hamburg University of Technology, Hamburg, Germany. \\ Email: helena.barbas@tuhh.de \\ Thomas Schramm, Geodesy and Geoinformatics, HafenCity University Hamburg, Hamburg, \\ Germany. Email: thomas.schramm@hcu-hamburg.de
}

\begin{abstract}
MINTFIT is a joint project of the HafenCity University Hamburg (HCU), Hamburg University of Applied Sciences HAW), Hamburg University of Technology (TUHH) and Universität Hamburg $(\mathrm{UHH})$ together with the Hamburg Ministry of Science, Research and Equalities (Behörde für Wissenschaft, Forschung und Gleichstellung, BWFG) to support high school students and others interested in STEM studies. The MINTFIT Math Test is a diagnostic online test which gives its participants the opportunity to check if their math skills are sufficient for a successful start into the first terms of a STEM degree programme.
\end{abstract}

Keywords: STEM study preparation, math skills diagnostic, first year problems.

\section{Introduction}

Many first-year students of STEM degree programmes have difficulties with mathematics at a university level. Mathematics is a common reason why students drop out of university in the first semesters. Daily experience shows that many first-year students lack basic skills regarding high school mathematics and that their problems with the new content are due to this fact. It is important to note that these students often do not lack only competencies from the upper secondary (see ISCED 1997, International Standard Classification of Education) level 3 but also from the lower level 2 and even from primary education. In order to point out this problem to them as soon as possible before they start with the first semester - and to help them to close their gaps, a concept of a diagnostic online test (the MINTFIT Math Test) and online mathematics bridging courses (OMB+ and viaMINT) has been developed at and with the support of universities of Hamburg within the scope of the MINTFIT project.

\section{Academics and Pedagogical Background}

At least in Germany the school pedagogics changed in many ways over more than twenty years. At first it changed from an input- to an output-oriented teaching. This means a change from the description of what is taught to what is learnt. Second, it turned from the transmission of knowledge to the acquisition of competencies of certain levels. In Bloom's Taxonomy (see Bloom, 1956) we find for the cognitive domain: knowing, applying, analyzing, synthesizing and evaluating as elementary levels of competencies. However, it is often criticised that "knowing" comes a little short in actual classrooms at schools and the sustainability of these competencies are not in their focus. At the universities we can just state that the freshmen often do not have the competency to work e.g. with fractions, quadratic equations or right triangles at any level. As some reasons we identify the early and exclusive use of the pocket calculator for even easy calculations, that not enough time is spent for basic practice and that the basic competencies are not used at higher grades any more so that they can be forgotten or spilled (compare Risse et al., 2008). Although administrations have already recognised these problems and some actions are under way, the mathematical competencies of 
freshmen are still decreasing. There are few studies published, but one study which supports this view has been done over ten years of testing the mathematical knowledge of freshmen at German Fachhochschulen (polytechnics) in the federal state of North Rhine-Westphalia (see Knospe, 2017). The overriding impression is that the objective of mathematics at schools is not the preparation for a STEM degree programme, at least not with high priority.

\section{The Transition from High School to University (cosh-Katalog)}

In Germany, the subject matters taught in high school differ between the federal estates. Additionally, there is a huge variety of ways to achieve a university entrance qualification. Consequently, the level of knowledge of the students in a math course at a university varies broadly. As a lecturer, it is difficult to identify which subjects can be assumed to be known. The fact that students come with different backgrounds in mathematics because they got their university entrance qualification in different ways and in different parts of the country is one more reason for the problems that arise at university.

In 2014, a group of high school teachers, professional school teachers and university professors of institutions in the German federal state Baden-Württemberg published a paper which caused quite a stir at the community of math teaching university staff. This group, which calls themselves "cosh" (short for "Cooperation Schule-Hochschule", in English "cooperation high school-university") defined a set of competencies and associated problems that should be taught at high schools in BadenWürttemberg and which has been accepted as a minimum of assumed knowledge at the start of a STEM degree programme, see Cooperation Schule-Hochschule (2014). Therefore, if a high school student or a person with another educational background decides to begin a STEM degree programme in Baden-Württemberg, he or she knows which subjects have to be mastered - and especially where he or she has to put some efforts before the first semester starts.

Shortly after the publication of this cosh catalogue, many universities in Germany decided to follow this compromise originally made only for a part of Germany and to assume the knowledge defined in the cosh catalogue for the students of the first semester of their STEM degree programmes. For example, the universities of the group TU9 (a group of nine big technical universities in Germany) now accept this cosh catalogue, and each of the universities in Hamburg which offer a STEM degree programme. These are the HafenCity University Hamburg, the Hamburg University of Applied Sciences, the Hamburg University of Technology and the Universität Hamburg. For the history of the cosh group and the cosh catalogue, see also Dürrschnabel and Wurth (2015). For an alternative overview compare also Schramm (2015).

The mathematical knowledge and competencies defined in the cosh catalogue covers a wide range of topics: elementary algebra, geometry/trigonometry, calculus, linear algebra and stochastics. Each topic is divided in further subtopics: e.g. for calculus, it is divided into functions, differential calculus and integral calculus. For a subtopic like differential calculus, a list of skills the freshmen should possess are defined:

- they should have a propaedeutic knowledge of limits,

- understand the derivative as the slope of a tangent to a curve as well as a rate of change,

- know how a function and its derivative relate and

- can conclude the graph of the derivative of a function from the function itself (and the other way),

- know the derivatives of elementary functions,

- can use the basic rules of differentiation,

- use the derivative to analyze a function regarding monotonicity and extrema,

- and know how to use differentiation to solve optimization problems. 
Each skill in the list comes with a few problems which freshmen should be able to solve - they must be viewed as a mean to define the level and should not be understood as an all-embracing definition of problems that should be mastered.

\section{The MINTFIT Math Test}

MINT in German is an abbreviation of "Mathematik, Informatik, Naturwissenschaften, Technik" which translates to "mathematics, computer sciences, natural sciences, technology". It is an equivalent of STEM.

The MINTFIT Math Test is a free diagnostic online test for high school students and those interested in STEM degree programmes. After finishing the test, the participants instantly get a feedback in which subjects of high school mathematics they should still put some efforts before beginning their university studies. Furthermore, two online learning platforms with mathematics bridging courses the OMB+ and viaMINT - are presented, the recommended chapters in both courses are highlighted. The OMB+ was developed with the support of the HCU, TUHH and the UHH. viaMINT is a product of the HAW.

The questions asked in the MINTFIT Math test are mathematically based on the mathematics knowledge competencies defined in the cosh catalogue (see above).

The MINTFIT Math Test is originally in German, but is now available also in English since 2017. It is accessible via www.mintfit.hamburg.

\section{The Structure of the MINTFIT Math Test}

The MINTFIT Math Test consists of the two separate tests Basic Skills I and Basic Skills II. Basic Skills I includes questions dealing with fractions and exponents and is based loosely on the subject matters taught in junior high school. Basic Skills II tests the skills in more advanced areas such as differential and integral calculus. It is based loosely on the subject matters of senior high school. Together, the two tests cover the subject matters defined by the cosh group in the cosh catalogue. Each of the separate tests should be finished in 45 minutes. This is just a recommendation, because there is no time limit. The test results and the suggestions which skill areas to review do not take the time consumed into account.

Basic Skills I consists of 22 questions, Basic Skills II of 14 questions. For each area such as fractions or differential calculus, two questions are randomly drawn out of a pool of questions. The test runs on the free and open source software course and learning management system Moodle. Many questions are written using the Moodle plug-in STACK. This plug-in allows random generation of a huge variety of versions of one only question within structured templates.

All questions were developed so that they can and should be solved by doing the calculations on paper and sometimes also by mental arithmetic. It is pointed out in the information that neither a calculator nor a formulary should be used. Since the test is designed as a test which can be taken at home, participants are only committed to themselves to honesty. Participants can choose the order and the times when they want to complete the tests. Before starting with the first of the two separate tests, they have to complete a short preparatory section consisting of four tasks. These serve to show how to enter mathematical expressions. The tasks in the tests themselves are designed such that the input is as simple as possible. During the entire tests, a symbol key is available on the edge of the page displaying how to input mathematical expressions. 


\begin{tabular}{|l|l|}
$\begin{array}{l}\text { Question } 21 \\
\text { Not yet answered }\end{array}$ & $\begin{array}{l}\text { Are the following sentences true or false? } \\
\text { The total of the interior angles of each triangle is } 90^{\circ}\end{array}$ \\
$\begin{array}{l}\text { Marked out of } 1.00 \\
\text { P Flag question }\end{array}$ & $\begin{array}{l}\text { Every quadrilateral in which all sides are equal is a } \\
\text { trapezoid. }\end{array}$ \\
\hline \begin{tabular}{l} 
A circle of radius $r$ has the circumference $\pi r^{2}$. \\
\hline \\
The total length of two sides of every triangle is always \\
less than the third side.
\end{tabular} & Not answered \\
\hline
\end{tabular}

Figure 1. Questions from the test Basic Skills I

In both tests, there are different types of questions (compare e.g. figure 1 to figure 3a). There are arithmetic problems, where the capacity to do calculations is tested. There are also multiple choice and true or false questions, and as well questions where rules or laws such as the laws of logarithm shall be put in. The used question types are from a set of possibilities defined by the IMS QTI specification (compare IMS GLOBAL).

\section{The Feedback for the Participants}

The results of a test are displayed immediately after participants complete this test. At the top of the results page, a medal is shown which expresses a feedback in a visual way. The medal is available in gold, silver, bronze and blue (figure 2). It is a face either smiling or with a neutral expression, depending on how good the result was. This medal is called "Plietschi", "plietsch" meaning "clever" in Low German language which is typically spoken in Northern Germany.

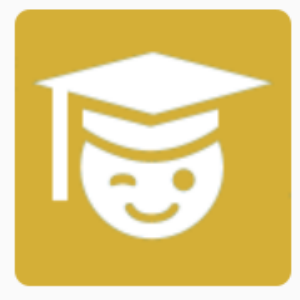

\section{Gold}

\section{Congratulations, you did an excellent job!}

You were able to successfully use your math skills in almost all of
the skill areas. However, to make sure that you have a successful
start with your STEM degree program, you should review certain
topics.

In the following, you can see which skill areas in Basic Skills I we recommend you review as part of your preparations for a MINT degree program. If you prepare well, you will find it easy to focus on the fascinating new content introduced in math at the university level.

Figure 2. General feedback for test results that are between $33 \%$ and $66 \%$ (Silver) and between $66 \%$ and $99.9 \%$ (Gold) of the maximum result.

A text describes the result and suggests how much effort participants should put in their study of mathematical basics. The score in the form of a percentage of maximum available points is not displayed, because it had a discouraging effect on the participants at an early stage of the development of the test. For each question, there is a standard solution shown as well as the solution that the participant gave. Additionally, if it is mathematically and technically possible, there is a specific feedback for wrong solutions indicating which mistakes were made. With the help of decision 
trees, the system gives these specific feedbacks as well as partial points for partially correct answers or consequential errors (figure $3 a$ and figure $3 b$ ).

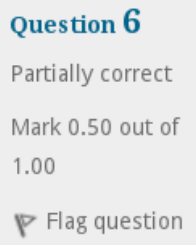

Figure 3a. The system checks if the second answer is consistent with the first (wrong) answer.

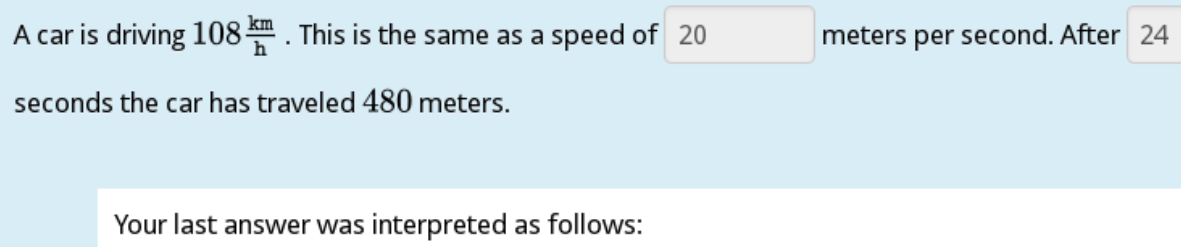

\begin{abstract}
The speed is not correct. To obtain this, you need to calculate $\frac{108 \cdot 1000}{3600}$.
The number of seconds necessary to travel 480 meters is incorrect. To obtain this, you must divide 480 by the number of meters traveled per second (30).

The number of seconds is however consistent with the speed you calculated.

Since one hour has 3600 seconds and a kilometer is 1000 meters, in 3600 seconds the car travels 108000 meters or $\frac{108000}{3600} \frac{\mathrm{m}}{\mathrm{s}}=30 \frac{\mathrm{m}}{\mathrm{s}}$. The car therefore travels 30 meters in one second and then needs $\frac{480}{30}$ seconds to travel 480 meters. Therefore, the answer is 16 seconds.
\end{abstract}

A correct answer is 30 , which can be typed in as follows: 30

A correct answer is 16 , which can be typed in as follows: 16

Figure 3b. Specific feedback for the consequential error.

On the subpage "Persönliche Übersicht" ("Personal Overview"), participants can see their test results broken down to the specific areas. For each area, the percentage of achieved points is displayed as well as a visual feedback in form of zero to four golden stars. If participants choose to repeat the test, for each area the best result of all attempts is shown. On this page, there are also listed the corresponding chapters of the two online mathematics bridging courses OMB+ and viaMINT. With a click on the logo of one of these courses, participants can (after accepting with another click) create an account on the chosen learning platform. The results of the test are then sent to the chosen platform, and the recommended chapters are highlighted on the learning platform. Participants can work either on one of the platforms, or on both at the same time.

For the future, it is planned to implement the other direction of information transport - if a participant chooses one platform and passes the final exam of the recommended chapter, the learning progress will be shown as well at the MINTFIT test page in the Personal Overview. 


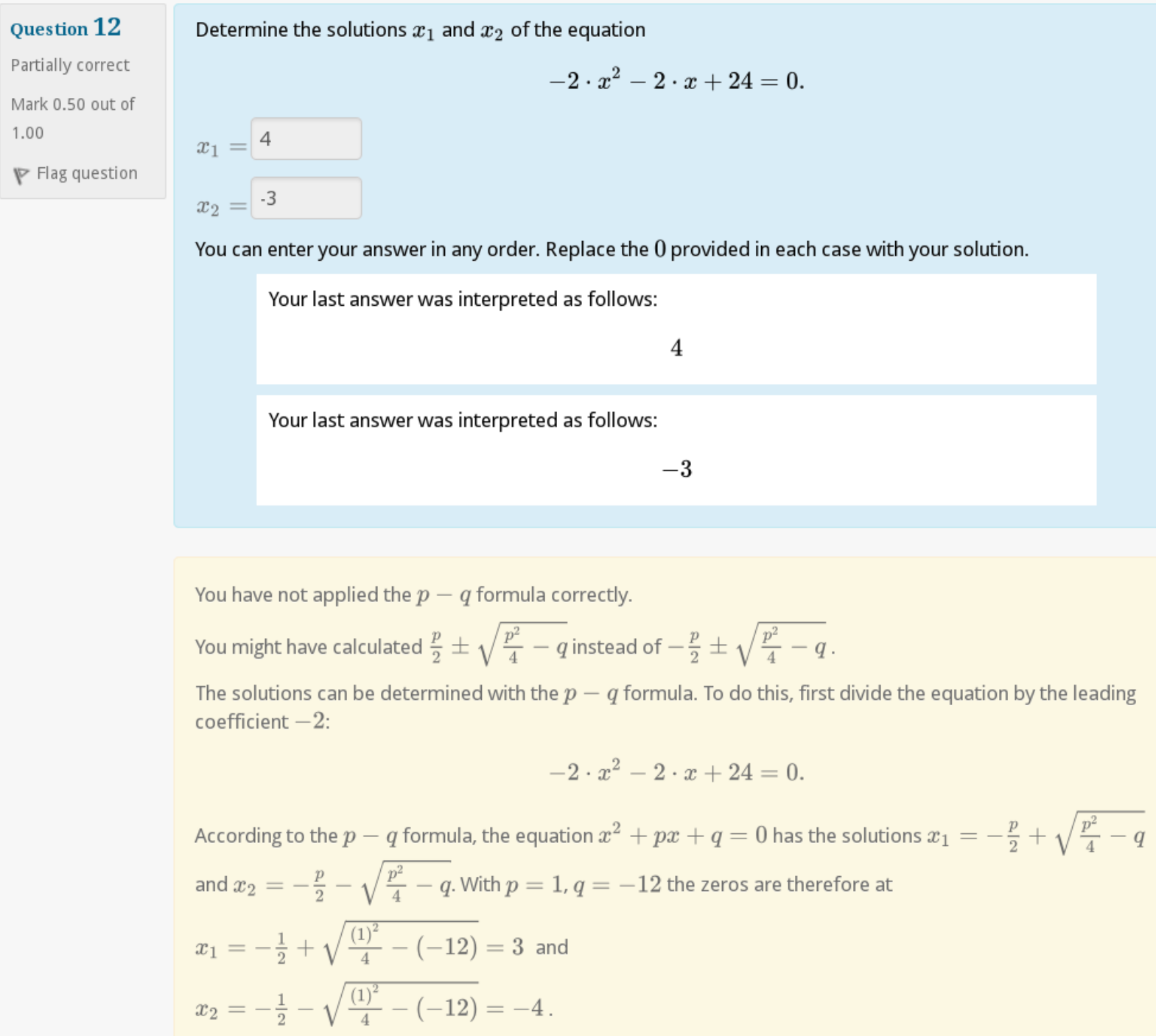

Figure 4. Specific feedback for a wrong result. Here, the system checks for common errors in applying the $p-q$ formula.

\section{The Learning Platforms OMB+ and viaMINT}

The Online Mathematik Brückenkurs Plus OMB+ (Online Mathematics Bridging Course Plus OMB+) is a joint project of 14 German universities and the company integral learning $\mathrm{GmbH}$. The development was managed by the $\mathrm{OMB}+$ consortium under the auspices of TU9. Its predecessor was the OMB, a cooperation between several German universities and the KTH Royal Institute of Technology in Stockholm. For legal purposes it was completely reengineered and extended in the years $2013 / 2014$ by the OMB+ consortium and is online accessible since November 2014. Authors of the HafenCity University Hamburg, the Hamburg University of Technology and the Universität Hamburg were involved in the development. The OMB+ offers its participants the opportunity to repeat and complement high school mathematics. It addresses those interested in STEM degree programmes and covers the subject matters defined in the cosh catalogue. The approach is text oriented, but there are many questions, interactive elements and also videos. A lot of examples with standard solutions which can be uncovered step by step are presented as well as a huge amount of training questions. Meanwhile, 40 German universities, the Deutsche Physikalische Gesellschaft DPG (German Physical Society), the NRW StudiFinder (an online tool for self-assessment and information about study programmes) and the platform Studiport (an online platform supporting freshmen with their start of university studies) use and recommend the $\mathrm{OMB}+$. The $\mathrm{OMB}+$, originally 
only in German, is available in English since March 2016. Further chapters covering e.g. stochastics, complex numbers and formal logic as well as more supplementing educational videos are currently in production. See www.ombplus.de.

viaMINT is an online learning platform for bridging courses developed and nearly completed by Hamburg University of Applied Sciences (HAW) and funded by the Bundesministerium für Bildung und Forschung BMBF (Federal Ministry of Education and Research). In viaMINT first-year students can find different bridging courses on one common learning platform. The mathematics bridging course has been available for several semesters. The physics course is still being developed. viaMINT has a video oriented approach with supplemental exercises. It includes numerous examples, animations and interactive applets that serve as visualizations. Supplement material such as the formula sheet are included to support the sustained learning. Students using viaMINT work in a personalised learning environment, the "Persönlicher Online-Schreibtisch" (Personal Online Desk). The Personal Online Desk supports organised study by visually indicating the study recommendations on the basis of an entrance test as well as the corresponding learning progress. Fitting the specific needs of each individual student, viaMINT offers different learning opportunities e.g. a "Detailed Learning Track" and a "Short Learning Track". As further supplement, custom-fit courses with on-site attendance are held at the Hamburg University of Applied Sciences. viaMINT is available in German. An English translation is in progress. A distinction for different degree programmes is scheduled. A more detailed description of viaMINT is available in Landenfeld et al. (2014) and Landenfeld et al. (2016). See viamint.haw-hamburg.de.

\section{Additional Use of the MINTFIT Math Test}

At the HafenCity University the MINTFIT Math Test and the bridging courses OMB+ and viaMINT are recommended for a parallel use in the first year courses in engineering mathematics. The classroom online test (just to pass) is mandatory but could be repeated as often as necessary. As is typical for practiced e-assessments, $80 \%$ must be achieved. The actual lecture can so be focused on university mathematics. First results show a strong correlation between the passing of the test and success in the final examination. Additionally, in Hamburg there are special rules for persons without a German "Abitur", but three years of vocational experience. They can apply for an examination to be accepted as a student for a particular programme. Following the idea that the most important obstacle for a successful STEM study programme is mathematics and that the minimum competencies are defined in the cosh catalogue, we use a variant of the MINTFIT Math Test as the major part of the examination. The candidates can prepare themselves using the mintfit.hamburg portal and get an immediate result.

Additionally, the HCU maintains many cooperations with schools and encourages the use of their mathematical eAssessment system Maple T.A. ${ }^{\circledR}$ (Maplesoft ${ }^{\mathrm{TM}}$ ) that offers more possibilities than Moodle for formative assessment in the classroom. For that purpose, we translated the MINTFIT questions to that system which offers the teachers the possibility to easily combine the questions to own assessments fitting to their current need.

Since 2016, a copy of the MINTFIT Math Test has been used with the freshmen at the Hamburg University of Technology. They can earn bonus points which can be used to slightly improve their result in the Linear Algebra written examination at the end of the first term.

\section{Reception and Evaluation of the MINTFIT Math Test}

It is too early to have a final evaluation of the whole project with math test and learning platforms. In general, it would be very difficult to measure if our activities have an impact on the drop-out rates in STEM degree programmes. However, there are some strong hints that they are helpful for students and that it is recognized by them. A representative subset of participants completed a survey after finishing the math test. A huge majority classified our test with a median of 1 as helpful for freshmen on a scale from 1 (best) to 5 (least). 
In one mathematics course at the HafenCity University Hamburg, the math test is mandatory. There is a strong positive relation between the results in the math test and the final mathematics exam grades.

On workshops on the subject, we got the feedback from mathematics teachers at high schools in Hamburg that the math test is highly estimated because their students get an impression of what is demanded at the institutions of higher education.

\section{A Look into the Present Activities and the Near Future}

In the summers of 2016 and 2017, we offered an on-site attendance bridging course "Math Camp" for all those interested in a STEM degree programme at one of the universities in Hamburg. It was separated in two parts, one covering the matters of Basic Skills I, the other part covering Basic Skills II. Each part was offered at two levels. After taking the MINTFIT Math Test, participants got a recommendation which course to attend and at which level. After these courses, the "Free Practice" started, which is a course over half a year, starting weeks before courses of the first semester begin and ending when courses at the universities end. In these courses, students or even high school students got the opportunity to work with tutors on their basic skills using exercises from the OMB+ and viaMINT. Taking the experiences from the first two runs, the course is now offered in summer 2018 to prepare for the winter term 2018.

The MINTFIT Math Test will be continuously complemented with new questions. A similar concept of online test and online course for physics is in the making, the physics test is already available in German and is currently being translated into English. Also, a test specifically composed for the needs of students at the Universität Hamburg (UHH) of a business, economics or social sciences degree programme has been published in 2018.

\section{References}

Bloom, B., Krathwohl, D. and Masia, B., 1956. Taxonomy of Educational Objectives. New York: Longman.

Cooperation Schule-Hochschule, 2014. Mindestanforderungskatalog Mathematik (Version 2.0) der Hochschulen Baden-Württembergs für ein Studium von WiMINT-Fächern. Available at: https://www.hs-karlsruhe.de/fileadmin/hska/SCSL/Lehre/makV2.0B ohne Leerseiten.pdf

[Accessed 14 June 2017].

UNESCO, 1997. International Standard Classification of Education (ISCED 1997). Available at: http://www.unesco.org/education/information/nfsunesco/doc/isced 1997.htm [Accessed 29 March 2018].

Dürrschnabel, K. and Wurth, R., 2015. cosh - Cooperation Schule-Hochschule. Mitteilungen der DMV, 23(3), pp. 181-185. Available at:

https://www.mathematik.de/ger/presse/ausdenmitteilungen/artikel/dmvm-2015-0067.pdf [Accessed 14 June 2017].

IMS GLOBAL Learning consortium, 2015. IMS Question \& Test Interoperability ${ }^{\circledR}$ Specification. Available at: https://www.imsglobal.org/question/index.html [Accessed 14 June 2017].

Knospe, H., 2017. Zehn Jahre Eingangstest Mathematik an Fachhochschulen in Nordrhein-

Westfalen. Available at: http://www.nt.th-

koeln.de/fachgebiete/mathe/knospe/10jeingangstest knospe.pdf [Accessed 29 March 2018]. 
Landenfeld, K., Göbbels, M., Hintze, A. and Priebe, J., 2014. viaMINT - Aufbau einer OnlineLernumgebung für videobasierte interaktive MINT-Vorkurse. Zeitschrift für Hochschulentwicklung, 9 (5), pp. 201-217. Available at: http://www.zfhe.at/index.php/zfhe/article/view/783/642 [Accessed 14 June 2017].

Landenfeld, K., Göbbels, M. and Hintze, A., 2016. A customized learning environment and individual learning in mathematical preparation courses. 13th International Congress on Mathematical Education, Hamburg, Germany, July 24-31 2016, to be published in: ICME Monograph Distance Learning, E-Learning and Blended Learning of Mathematics: International Trends in Research and Development.

Maplesoft, 2017. Maple T.A. Available at: http://www.maplesoft.com/products/Mapleta/ [Accessed 14 June 2017].

Risse, T., Schott, D., Schramm, T. and Strauß, R., 2008. Positions to Mathematical Education of Engineers. 14th SEFI Conference, Loughborough, 2008. Available at: http://sefi.htwaalen.de/Seminars/Loughborough2008/mee2008/proceedings/mee2008F risse etal.pdf [Accessed 14 June 2017].

Schramm, T., 2015. Mintstudium Hamburg - Eine konzertierte Aktion. Proc. 12. Workshop Mathematik für Ingenieure, HCU Hamburg 2015, Frege-Reihe Hochschule Wismar, Dieter Schott (editor) 02/2015. 